\title{
Molecular breeding of thermo-sensitive genic male sterile (TGMS) lines of rice for blast resistance using Pi2 gene
}

\author{
Jiefeng Jiang ${ }^{1}$, Tongmin Mou ${ }^{1 *}$, Huihui $\mathrm{Yu}^{2}$ and Fasong Zhou ${ }^{2}$
}

\begin{abstract}
Background: Blast disease caused by the fungal pathogen Magnaporthe oryzae is one of the big problems in rice production in China, especially for high yield hybrid varieties made from a two-line system in which thermo-sensitive genic male sterile (TGMS) lines are used. In this study, we report the introgression of a rice blast resistance gene Pi2 from VE6219 into C815S, an elite rice TGMS line, leading to the development of blast resistant TGMS lines through marker assisted selection (MAS) and phenotypic selection approaches.

Results: Four new TGMS lines with blast resistance gene Pi2 were developed from C815S (an elite TGMS line susceptible to the blast, used as recurrent parent) and VE6219 (a blast resistant line harboring Pi2, used as donor parent). The pathogenicity assays inoculated with 53 blast prevalent isolates in glasshouse showed that the blast resistant frequency of the four TGMS lines was 94.3\%-98.1\% that is equivalent to blast resistant donor parent VE6219. The field evaluation of the new lines and hybrids made from them at a blast epidemic site also showed high resistant levels against the blast. The genetic background of the newly developed TGMS lines were examined using a whole-genome single nucleotide polymorphism (SNP) array (RICE6K) that turned out more than $83 \%$ of the genomic markers were derived from the recurrent parent. The critical temperature points of fertility-sterility alteration of the new TGMS lines were between $22^{\circ} \mathrm{C}$ and $23^{\circ} \mathrm{C}$ of daily mean temperature, which is similar to that of C815S. The complete male sterility under natural growth conditions at Wuhan last more than 80 days. Their agronomic and grain quality traits meet the requirement for two-line hybrid rice production.

Conclusions: The broad-spectrum and durable rice blast resistant gene Pi2 was introgressed into the elite TGMS line C815S background. The newly developed TGMS lines can be practically used for two-line hybrid rice breeding and must play an important role in sustainable rice production in China.
\end{abstract}

Keywords: Rice blast resistance; TGMS line; Two-line hybrid rice; Marker-assisted selection; Pi2

\section{Background}

Rice blast caused by Magnaporthe oryzae is the most destructive diseases widely prevalent in rice fields, leading to significant grain yield and quality reduction. The disease including leaf and panicle blast can cause yield losses from $10 \%$ to $30 \%$ in severely infected crops (Skamnioti and Gurr 2009). It has been a major problem for hybrid rice production due to the large area

\footnotetext{
* Correspondence: tongmin58@mail.hzau.edu.cn

'National Key Laboratory of Crop Genetic Improvement, National Center of Plant Gene Research (Wuhan), Huazhong Agricultural University, Wuhan 430070, China

Full list of author information is available at the end of the article
}

monoculture of a crop variety and quickly evolved major race of the pathogene (Bonman et al. 1986; Liu et al. 2010).

So far, 86 blast resistance genes have been documented (Liu et al. 2013). A few of them have already been incorporated into rice varieties, which are now widely cultivated in many countries. The rice blast resistance gene Pi2 was introduced from a resistant indica rice cultivar 5173 into a susceptible cultivar CO39, and the derived isogenic line was named C101A51 (Mackill and Bonman 1992). At least six resistance genes (Pi2, Pi9, Piz-t, Piz, Pigm and Pi50) were mapped at the same location, close to the centromere of chromosome 6 (Deng et al. 2006; Hayashi et al. 2004; Liu et al. 2002; Zhu et al. 2012). Pi2 
is one of the broad spectrum resistance genes highly effective in rice blast control. Lines carrying Pi2 were tested with 43 blast isolates collected from 13 countries and showed resistant to 36 of them (Liu et al. 2002). Pi2 gene has been isolated and characterized, which encodes a NBS-LRR (a nucleotide-binding site and leucine-rich repeat) protein (Zhou et al. 2006). Marker-assisted selection (MAS) has become an important approach to the development of disease resistance cultivars, especially in the utilization of cloned genes, which largely reduces time and cost in breeding programs (Ishihara et al. 2014; Jiang et al. 2012; Narayanan et al. 2002). In this study we employed MAS to develop thermo-sensitive genic male sterile (TGMS) lines by introducing Pi2 into the TGMS background.

Comparing with three-line rice hybrid production system, two-line system with TGMS has some advantages: (1) The male sterility were controlled by recessive nuclear genes. Any genotype with good combining ability can be used as a male parent. The frequency of obtaining heterotic hybrids in testcrosses is relatively higher than three-line system. (2) It can be used to develop hybrids of japonica or basmati in which there are very low frequency of cytoplasmic male sterile (CMS) restorers. (3) It is especially suited for developing sub specific hybrid (indica/japonica) because there is no restriction of restoring-maintaining relationship in TGMS system. (4) The cost for hybrid seed production is lower as compared to the three-line system. Two-line hybrid breeding has been widely used in China as an effective approach to the improvement of rice grain yield and quality. However, there is an urgent need to enhance its blast disease resistant. Here we report the line breeding process and main results in the development of TGMS lines with broad spectrum resistance to blast through MAS, and the subsequent check of their genetic background with the aid of a rice genomic SNP array.

\section{Results}

Introgression of rice blast resistance gene Pi2 by MAS

$F_{1}$ plants obtained from the cross of C815S (an elite TGMS line) and VE6219 (carrying Pi2), were screened for presence of the target resistance gene Pi2 using the gene linked molecular marker RM527 to identify the true $\mathrm{F}_{1}$ s showing heterozygous and were backcross with C815S in summer season of 2008 at Wuhan. Of $40 \mathrm{BC}_{1} \mathrm{~F}_{1}$ plants, 16 individual plants were identified to be positive for Pi2 using the marker RM527. In $\mathrm{BC}_{1} \mathrm{~F}_{1}$, two selection strategies were taken in the subsequent generations (Figure 1). One is to select positive fertile plants and to be used for further backcrossing with C815S. Other is to select male sterile plants that would be ratooned under low temperature for harvesting $\mathrm{BC}_{1} \mathrm{~F}_{2}$ seeds. The advanced backcross progenies of $\mathrm{BC}_{2}$ and $\mathrm{BC}_{3}$ were generated from the crosses of selected positive $\mathrm{BC}_{1} \mathrm{~F}_{1}$ (16 plants from 40) and $\mathrm{BC}_{2} \mathrm{~F}_{1}$ (14 plants from 40) by MAS (Figure 1). The same method was repeated for advancing the next generation to reach $\mathrm{BC}_{2} \mathrm{~F}_{2}$ and $\mathrm{BC}_{3} \mathrm{~F}_{2}$. The male sterile plants with homozygous Pi2 were selected in $\mathrm{BC}_{1} \mathrm{~F}_{2}, \mathrm{BC}_{2} \mathrm{~F}_{2}$ and $\mathrm{BC}_{3} \mathrm{~F}_{2}$ populations and ratooned under low temperature to obtain next generation seeds. Finally, we developed four TGMS lines that harbored the homozygous marker linked to Pi2 and also showed desirable agronomic traits in different backcross generations, which were designated as Hua1034S $\left(\mathrm{BC}_{1} \mathrm{~F}_{6}\right)$, Hua1032S $\left(\mathrm{BC}_{2} \mathrm{~F}_{6}\right)$, Hua1033S $\left(\mathrm{BC}_{2} \mathrm{~F}_{6}\right)$, and Hua1037S $\left(\mathrm{BC}_{3} \mathrm{~F}_{6}\right)$ (Figure 1 and Figure 2).

\section{Genetic background examination of the newly developed TGMS lines}

In this study, RICE6K, a whole-genome single nucleotide polymorphism (SNP) array was used to to analyze the genetic background of the newly developed TGMS lines. The identified high quality markers, 1256 out of 5102, showed polymorphisms between the recurrent parent, C815S, and the donor parent, VE6219. The genetic background recovery of the recurrent parent in Hua1032S, Hua1033S, Hua1034S and Hua1037S were 83.93\%, $88.47 \%, 83.15 \%$ and $88.93 \%$, respectively, measured by percentage of the polymorphic marker ratios (Figure 3). All four TGMS lines had large fragments of chromosome 6 because of foreground Pi2 selection in each generation by MAS. These four TGMS lines must be further selfpollinated and selected since several fragments in each TGMS line were still heterozygous.

\section{Evaluation of blast resistance}

Leaf blast resistances of the newly developed TGMS lines and the two parents were assessed using 53 isolates of $M$. oryzae from Zhejiang and Guangdong provinces, China, in greenhouse. The donor parent VE6219, containing Pi2 gene, showed broad-spectrum resistance to rice blast with a high resistance frequency of $90.6 \%$, and the recurrent parent $\mathrm{C} 815 \mathrm{~S}$ was found susceptible to the most of isolates with the resistance frequency of $34.0 \%$. The developed TGMS line Hua1037S was resistant against 50 of 53 blast isolates with a resistance frequency of $94.3 \%$ slight higher resistance frequency as of VE6219. Other improved TGMS lines viz. Hua1032S, Hua1033S and Hua1034S with $98.1 \%$ resistance frequencies showed higher resistance frequency than VE6219 (Table 1).

In order to evaluate the blast resistance of four TGMS lines and their derived hybrids in field, plants of each line were grown at Wangjia village of Yuan-An county, Hubei, China, where the altitude is about 600 meters, a hilly region with frequent blast epidemic in rice growing season, and it is a test site area for evaluation of the blast resistance of the China national rice regional test varieties. The results (Table 2) showed that C815S was 


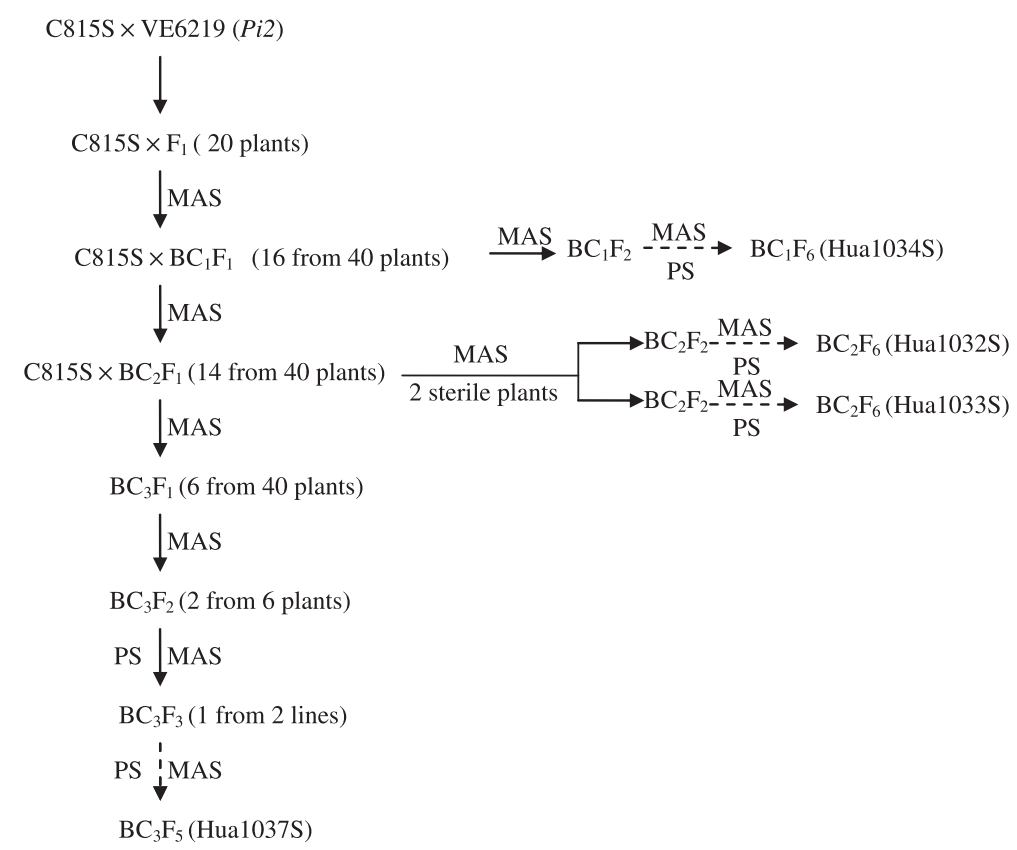

Figure 1 The scheme showing the development of rice blast resistant TGMS lines by introgression of rice blast resistant genes Pi2 (donor parent: VE6219) into the susceptible popular TGMS recipient parent, C815S, through MAS approaches. MAS: marker assistance selection; PS: phenotypic selection.

susceptible to rice blast with 7 score of leaf blast and $100 \%$ of neck blast incidence, respectively. The leaf blast scores and neck blast incidences of the four TGMS lines were less than 1 and 6\%, respectively, similar to donor parent VE6219. Two pollen parents (IR24 and R1005) and C815S' derived hybrids were susceptible to both leaf and neck blast. However, the hybrids derived from the four newly developed TGMS lines were resistant against leaf and neck blast (Table 2).

\section{Characterization of fertility-sterility alteration in growth chamber}

The critical temperature point (CTP) of fertility-sterility alteration has practical importance especially for a TGMS

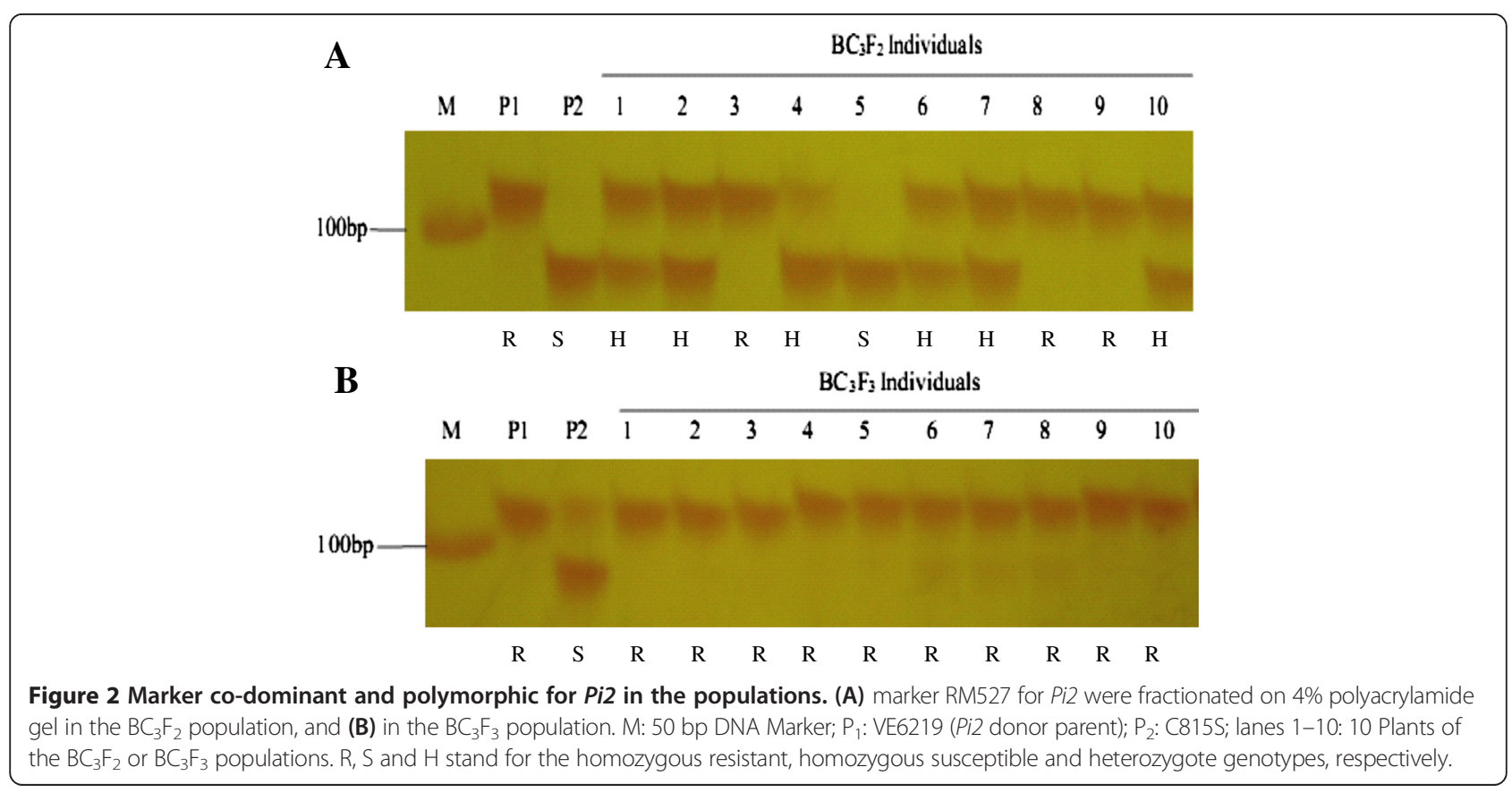



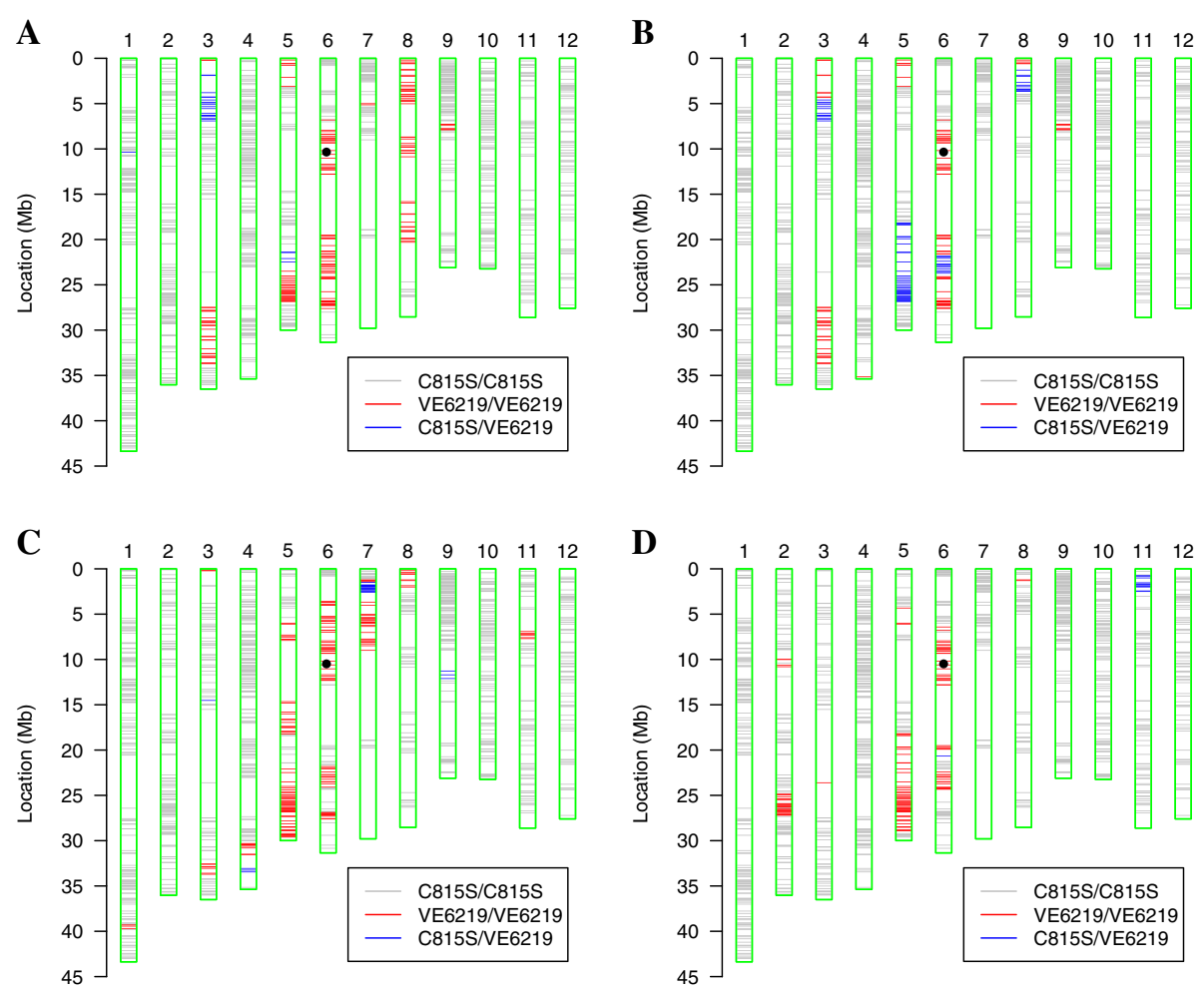

Figure 3 Haplotype maps of genetic background profiling using RICE6K array. (A) Hua1032S, (B) Hua1033S, (C) Hua1034S and (D) Hua1037S. The dots indicate the position of Pi2 on chromosome 6.

line to safe seed production. In this study, the plants were placed in five growth chambers while the daily mean temperatures (DMT) were set for $21^{\circ} \mathrm{C}, 22^{\circ} \mathrm{C}, 23^{\circ} \mathrm{C}, 24^{\circ} \mathrm{C}$ and $25^{\circ} \mathrm{C}$ from $5-16$ days after panicle initiation primordial stage for 12 days. The pollen grains collected from top five spikelets from each panicle per plant that headed during 5-16 days after the end of controlled growth chamber environment treatment were observed under microscope. The results showed that the pollen of the recurrent TGMS line i.e. C815S, was completely sterile (pollen sterility more than $99.5 \%$ ) in the growth chambers with $22^{\circ} \mathrm{C}$ onwards to $25^{\circ} \mathrm{C}$ of DMT, but became partial fertile under $21^{\circ} \mathrm{C}$, while the new TGMS lines, Hua1037S and Hua1034S had similar CTP of fertility-sterility alteration located in between $21^{\circ} \mathrm{C}$ and $22^{\circ} \mathrm{C}$ of DMT (Table 3). Therefore, it will be safe to carry out two-line hybrid seed production under conditions where DMT is higher than $22^{\circ} \mathrm{C}$. However, the pollen sterility of Hua1032S and Hua1033S were less than $99.5 \%$ under $23^{\circ} \mathrm{C}$ while completely sterile in growth chambers with $24^{\circ} \mathrm{C}$ to $25^{\circ} \mathrm{C}$ DMT (Table 3). So, the natural DMT should be higher than $24^{\circ} \mathrm{C}$ for seed production safely.

In China, a practical usable TGMS line needs a stable sterility period of longer than 30 days in given region. We sowed TGMS lines at 15-day intervals at the Experimental Farm of Huazhong Agricultural University
(HAU). The pollen fertilities in each line from the top five spikelets of primary panicles were investigated dynamically with two-day intervals under microscope from 30 June to 1 October. The pollen sterility data were recorded with average of five panicles from each line. The results showed that the pollen sterile periods of Hua1032S and Hua1033S were 88 days from 30 June to 26 September. Those of Hua1034S and Hua1037S were 80 days from 8 July to 26 September (Figure 4). Analysis of pollen sterility data in relation to temperature weather charts showed that when the DMT during 13 to 16 of September declined to below $22^{\circ} \mathrm{C}$, the pollen grains of developed TGMS lines and C815S had shown reversal to partial fertility around 26 September. These phenomena indicated that the sensitive stage to temperature located at 13 days before heading. Although the DMT declined to $22.2^{\circ} \mathrm{C}$ on 23 August, the pollen of TGMS lines remained completely sterile, indicating their CTPs under natural conditions being similar as in growth chamber (Table 3 and Figure 4).

\section{Evaluation of agronomic and rice quality traits of the newly developed TGMS}

Four newly developed TGMS lines were evaluated for their agronomic and grain quality traits as compared to C815S at the Rice Breeding Station of Hainan in the 
Table 1 Disease resistance reaction of newly developed TGMS lines (NT), recipient (RP) and donor parents (DP) along with susceptible check (SC) variety to 53 rice blast isolates under artificial inoculation in greenhouse

\begin{tabular}{|c|c|c|c|c|c|c|c|}
\hline Blast isolates & C815S & Hua1032S & Hua1033S & Hua1034S & Hua1037S & VE6219 & CO39 \\
\hline A13 & $\mathrm{R}$ & $R$ & $\mathrm{R}$ & $\mathrm{R}$ & $\mathrm{R}$ & $\mathrm{R}$ & $S$ \\
\hline A15 & $\mathrm{R}$ & $\mathrm{R}$ & $S$ & $\mathrm{R}$ & $\mathrm{R}$ & S & $S$ \\
\hline B01 & S & $R$ & $\mathrm{R}$ & $\mathrm{R}$ & $\mathrm{R}$ & $\mathrm{R}$ & S \\
\hline B05 & S & R & $\mathrm{R}$ & $\mathrm{R}$ & $\mathrm{R}$ & $\mathrm{R}$ & $S$ \\
\hline B09 & S & R & $\mathrm{R}$ & $\mathrm{R}$ & $\mathrm{R}$ & $\mathrm{R}$ & S \\
\hline B13(1) & $\mathrm{R}$ & $\mathrm{R}$ & $\mathrm{R}$ & $\mathrm{R}$ & $\mathrm{R}$ & $\mathrm{R}$ & S \\
\hline$B 13(2)$ & S & $\mathrm{R}$ & $\mathrm{R}$ & $\mathrm{R}$ & $\mathrm{R}$ & $\mathrm{R}$ & S \\
\hline B13(3) & S & R & $\mathrm{R}$ & $\mathrm{R}$ & $\mathrm{R}$ & $\mathrm{R}$ & S \\
\hline B13(4) & S & $R$ & $\mathrm{R}$ & $\mathrm{R}$ & S & $\mathrm{R}$ & S \\
\hline B13(5) & S & $\mathrm{R}$ & $\mathrm{R}$ & $\mathrm{R}$ & $\mathrm{R}$ & $\mathrm{R}$ & S \\
\hline $\mathrm{B} 13(6)$ & S & R & $\mathrm{R}$ & $\mathrm{R}$ & $\mathrm{R}$ & $\mathrm{R}$ & $S$ \\
\hline $\mathrm{B} 13(7)$ & S & $\mathrm{R}$ & $\mathrm{R}$ & $\mathrm{R}$ & $\mathrm{R}$ & $\mathrm{R}$ & S \\
\hline B13(8) & S & $R$ & $\mathrm{R}$ & $\mathrm{R}$ & $\mathrm{R}$ & $\mathrm{R}$ & S \\
\hline B13(9) & S & $\mathrm{R}$ & $\mathrm{R}$ & $\mathrm{R}$ & $\mathrm{R}$ & $\mathrm{R}$ & S \\
\hline B13(10) & $\mathrm{R}$ & R & $\mathrm{R}$ & $\mathrm{R}$ & $\mathrm{R}$ & S & S \\
\hline B13(11) & S & R & $\mathrm{R}$ & $\mathrm{R}$ & $\mathrm{R}$ & R & $S$ \\
\hline B15(1) & S & R & $\mathrm{R}$ & $\mathrm{R}$ & $\mathrm{R}$ & R & S \\
\hline B15(2) & S & R & $\mathrm{R}$ & $\mathrm{R}$ & $\mathrm{R}$ & $R$ & S \\
\hline B15(3) & R & R & $\mathrm{R}$ & $\mathrm{R}$ & $\mathrm{R}$ & R & $\mathrm{R}$ \\
\hline B15(4) & $\mathrm{R}$ & $R$ & $\mathrm{R}$ & $\mathrm{R}$ & $\mathrm{R}$ & R & $\mathrm{R}$ \\
\hline B15(6) & $\mathrm{R}$ & $R$ & $\mathrm{R}$ & $\mathrm{R}$ & $\mathrm{R}$ & R & $\mathrm{R}$ \\
\hline B15(7) & S & R & $\mathrm{R}$ & $\mathrm{R}$ & $\mathrm{R}$ & $\mathrm{R}$ & S \\
\hline C13(1) & S & R & $\mathrm{R}$ & $\mathrm{R}$ & $\mathrm{R}$ & $\mathrm{R}$ & S \\
\hline $\mathrm{C} 13(2)$ & S & R & $\mathrm{R}$ & $\mathrm{R}$ & $\mathrm{R}$ & R & S \\
\hline C13(3) & R & $\mathrm{R}$ & $\mathrm{R}$ & $\mathrm{R}$ & $\mathrm{R}$ & R & S \\
\hline C13(4) & S & $R$ & $\mathrm{R}$ & $\mathrm{R}$ & $\mathrm{R}$ & R & S \\
\hline C13(5) & R & R & $\mathrm{R}$ & $\mathrm{R}$ & $\mathrm{R}$ & R & S \\
\hline C13(6) & R & R & $\mathrm{R}$ & $\mathrm{R}$ & $\mathrm{R}$ & S & S \\
\hline C13(7) & R & $\mathrm{R}$ & $\mathrm{R}$ & $S$ & S & S & $S$ \\
\hline C15(1) & S & R & $\mathrm{R}$ & $\mathrm{R}$ & $\mathrm{R}$ & $R$ & $S$ \\
\hline C15(2) & S & $\mathrm{R}$ & $\mathrm{R}$ & $\mathrm{R}$ & R & R & $S$ \\
\hline C15(3) & R & $\mathrm{R}$ & $\mathrm{R}$ & $\mathrm{R}$ & R & R & S \\
\hline G01 & R & $\mathrm{R}$ & $\mathrm{R}$ & $\mathrm{R}$ & $\mathrm{R}$ & $\mathrm{R}$ & S \\
\hline B9(11-109) & S & $\mathrm{R}$ & $\mathrm{R}$ & $\mathrm{R}$ & $\mathrm{R}$ & R & S \\
\hline C15(12-103) & R & R & $\mathrm{R}$ & $\mathrm{R}$ & R & R & $S$ \\
\hline $\mathrm{C} 15(\mathrm{H}-1)$ & S & $\mathrm{R}$ & $\mathrm{R}$ & $\mathrm{R}$ & $\mathrm{R}$ & R & $S$ \\
\hline C15(10-151) & S & S & $\mathrm{R}$ & $\mathrm{R}$ & $\mathrm{R}$ & R & S \\
\hline B9(09-78-20) & S & $\mathrm{R}$ & $\mathrm{R}$ & $\mathrm{R}$ & $\mathrm{R}$ & $\mathrm{R}$ & $S$ \\
\hline C15(12-217) & S & $R$ & $\mathrm{R}$ & $\mathrm{R}$ & $\mathrm{R}$ & R & S \\
\hline C15(12-211) & S & $\mathrm{R}$ & $\mathrm{R}$ & $\mathrm{R}$ & $\mathrm{R}$ & R & S \\
\hline G1(10-85) & S & R & $\mathrm{R}$ & $\mathrm{R}$ & $\mathrm{R}$ & R & S \\
\hline C9(06-113) & R & $R$ & $\mathrm{R}$ & $\mathrm{R}$ & S & $\mathrm{R}$ & S \\
\hline C9(12-180) & S & $\mathrm{R}$ & $\mathrm{R}$ & $\mathrm{R}$ & $\mathrm{R}$ & $\mathrm{R}$ & $S$ \\
\hline
\end{tabular}


Table 1 Disease resistance reaction of newly developed TGMS lines (NT), recipient (RP) and donor parents (DP) along with susceptible check (SC) variety to $\mathbf{5 3}$ rice blast isolates under artificial inoculation in greenhouse (Continued)

\begin{tabular}{|c|c|c|c|c|c|c|c|}
\hline B9(06-234) & $\mathrm{S}$ & $\mathrm{R}$ & $\mathrm{R}$ & $\mathrm{R}$ & $\mathrm{R}$ & $S$ & $S$ \\
\hline B17(12-105) & $\mathrm{S}$ & $\mathrm{R}$ & $\mathrm{R}$ & $\mathrm{R}$ & $\mathrm{R}$ & $\mathrm{R}$ & $S$ \\
\hline D5(12-13) & $S$ & $\mathrm{R}$ & $\mathrm{R}$ & $\mathrm{R}$ & $\mathrm{R}$ & $\mathrm{R}$ & $\mathrm{S}$ \\
\hline G1(09-135) & $\mathrm{S}$ & $\mathrm{R}$ & $\mathrm{R}$ & $\mathrm{R}$ & $\mathrm{R}$ & $\mathrm{R}$ & $S$ \\
\hline$C 3(11-216)$ & $\mathrm{R}$ & $\mathrm{R}$ & $\mathrm{R}$ & $\mathrm{R}$ & $\mathrm{R}$ & $\mathrm{R}$ & $S$ \\
\hline $\mathrm{C} 3(\mathrm{H}-3)$ & $\mathrm{R}$ & $\mathrm{R}$ & $\mathrm{R}$ & $\mathrm{R}$ & $\mathrm{R}$ & $\mathrm{R}$ & $S$ \\
\hline $\mathrm{D} 5(\mathrm{H}-2)$ & $\mathrm{s}$ & $\mathrm{R}$ & $\mathrm{R}$ & $\mathrm{R}$ & R & $\mathrm{R}$ & S \\
\hline C9(06-263) & $\mathrm{S}$ & $\mathrm{R}$ & $\mathrm{R}$ & $\mathrm{R}$ & $\mathrm{R}$ & $\mathrm{R}$ & $S$ \\
\hline$E 3(11-109)$ & $\mathrm{R}$ & $\mathrm{R}$ & $\mathrm{R}$ & $\mathrm{R}$ & $\mathrm{R}$ & $\mathrm{R}$ & $S$ \\
\hline $\mathrm{B} 9(10-101)$ & $\mathrm{S}$ & $\mathrm{R}$ & $\mathrm{R}$ & $\mathrm{R}$ & $\mathrm{R}$ & $\mathrm{R}$ & $\mathrm{S}$ \\
\hline NO. of resistant isolates & 18 & 52 & 52 & 52 & 50 & 48 & 3 \\
\hline NO. of susceptible isolates & 35 & 1 & 1 & 1 & 3 & 5 & 50 \\
\hline Resistance frequency (\%) & 34.0 & 98.1 & 98.1 & 98.1 & 94.3 & 90.6 & 5.7 \\
\hline
\end{tabular}

winter season 2011-2012. The results (Table 4) showed non-significant differences for the days from sowing to heading, number of panicles per plant, 1000-grain weight, milling rice percentage, grain length and grain length-width ratio between the newly developed TGMS lines and C815S. The plant height of Hua1034S was higher than $\mathrm{C} 815 \mathrm{~S}$ by $6.5 \mathrm{~cm}$. The panicle lengths of all

Table 2 The performance of leaf and neck blast resistances for the four newly developed TGMS lines, their derived hybrids and control materials under the natural field of blast epidemic area

\begin{tabular}{lll}
\hline Entries & Score of leaf blast & Incidence of neck blast (\%) \\
\hline Hua1032S & 0 & 6.0 \\
Hua1033S & 0 & 5.0 \\
Hua1034S & 1 & 0.0 \\
Hua1037S & 0 & 3.0 \\
C815S & 7 & 100.0 \\
CO39 & 9 & 100.0 \\
VE6219 & 0 & 5.0 \\
Hua1032S/IR24 & 3 & 11.0 \\
Hua1033S/IR24 & 0 & 11.0 \\
Hua1034S/IR24 & 0 & 6.0 \\
Hua1037S/IR24 & 4 & 10.0 \\
C815S/IR24 & 5 & 29.0 \\
IR24 & 7 & 99.0 \\
Hua1037S/R1005 & 0 & 0.0 \\
Hua1032S/R1005 & 0 & 8.0 \\
Hua1033S/R1005 & 0 & 6.0 \\
Hua1034S/R1005 & 0 & 0.0 \\
C815S/R1005 & 4 & 39.0 \\
R1005 & 4 & 54.0 \\
\hline
\end{tabular}

four newly developed TGMS lines were longer than that of $\mathrm{C} 815 \mathrm{~S}$ by $2.1-3.7 \mathrm{~cm}$. The number of grains per panicle of Hua1033S and Hua1034S were more than that of C815S. The spikelet fertility of Hua1032S and Hua1033S, the very important trait in TGMS line multiplication, were $22-31 \%$ more than that of C815S. The gel consistency of all the developed TGMS lines were increased 15-29 mm compared with the recurrent parent, C815S. Another desirable grain quality trait was higher amylose content, thus increased taste for customer in China.

\section{Discussion}

The two-line system for hybrid rice production has been widely used in China for increasing rice grain yield. However, the prevalence of rice blast disease is jeopardizing the expansion of the popular hybrids as a result of their susceptibility to the disease. Thus, to enhance the blast resistance of the parental lines is essential for sustainable utilization of the high-yielding hybrids. In this study, we sought to improve rice blast resistance in C815S because several commercial hybrids using C815S as the female parent were widely grown in the indica

Table 3 Fertility-sterility alteration behavior of the newly developed TGMS lines and the recurrent parent under five different temperature regimes in growth chambers

\begin{tabular}{llllll}
\hline Entries & \multicolumn{5}{l}{ Pollen sterility (\%) } \\
\cline { 2 - 6 } & $\mathbf{2 \mathbf { 1 } ^ { \circ } \mathbf { C }}$ & $\mathbf{2 2}^{\mathbf{}} \mathbf{C}$ & $\mathbf{2 3}^{\circ} \mathbf{C}$ & $\mathbf{2 4}^{\mathbf{}} \mathbf{C}$ & $\mathbf{2 5}^{\circ} \mathbf{C}$ \\
\hline Hua1032S & 84.39 & 96.2 & 97.1 & 100.0 & 100.0 \\
Hua1033S & 81.29 & 95.3 & 99.4 & 100.0 & 100.0 \\
Hua1034S & 91.27 & 99.7 & 100.0 & 100.0 & 100.0 \\
Hua1037S & 86.48 & 100.0 & 100.0 & 100.0 & 100.0 \\
C815S & 69.62 & 99.5 & 100.0 & 100.0 & 100.0 \\
\hline
\end{tabular}




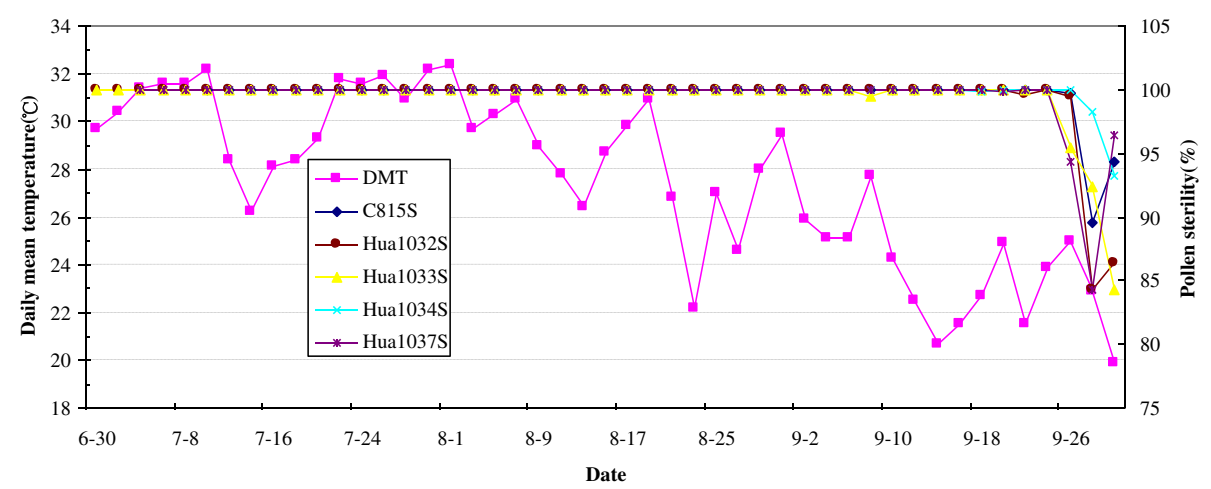

Figure 4 The dynamic pollen fertility expressions of the newly developed TGMS lines and C815S relative to daily mean temperature (DMT) data from 8th July to 1 st October in 2012 at Wuhan.

rice growing area of the Central and Southern China. The closely linked and diagnostic marker RM527 was used for tracking Pi2 in our breeding program, and the resistance gene was incorporated into C815S using backcrossing strategy. The newly developed TGMS lines, Hua1032S, Hua1033S, Hua1034S and Hua1037S, and the hybrids produced thereby, exhibited an elevated blast resistant. Our study clearly indicated that $\mathrm{Pi2}$ gene has a broad spectrum resistance to rice blast and is valuable for development of blast resistance rice hybrids. MASbased backcross schemes were shown effective in the improvement of TGMS line for the blast resistance.

The genetic background of the four selected TGMS lines was examined by using a genomic SNP array, RICE6K. The results showed that the genetic background was not recovered to the recurrent parent levels although 3 cycles of backcrosses were performed. To recover a maximum recurrent parent genetic background in a short time, breeders would need a large backcross population and do background selection on top of the foreground check for the target gene (Rajpurohit et al. 2011). Suh et al. (2013) reported more than $92.1 \%$ recovery of background of recurrent parent Mangeumbyeo in $\mathrm{BC}_{3} \mathrm{~F}_{5}$ with phenotypic selection without marker assisted background selection (MABS) during introgression of three bacterial blight resistance genes. In this project, we tried to develop new TGMS lines for stronger resistance against blast and with better agronomic traits to increase yields of the hybrid seeds, and our selections on the target traits obviously resulted in genetic drags. In our ongoing breeding program, we are using RICE6K to examine the genetic background of the selected lines and to more precisely remove the negative genetic drags. Interestingly, Hua1034S derived from $\mathrm{BC}_{1} \mathrm{~F}_{1}$ contains $83.15 \%$ of genetic loci from C815S, similar to that of Hua1032S (83.93\%) and Hua1033S (88.47\%), which were derived from $\mathrm{BC}_{2} \mathrm{~F}_{1}$ plants, and Hua1037S (88.93\%), which was derived from a $\mathrm{BC}_{3} \mathrm{~F}_{1}$ plant (Figure 1 ). It might be interpreted as that the recurrent genetic background was recovered faster than theoretically expected in early backcross generations because of selection on morphologic traits of the recurrent parent. In contrary, the recurrent genetic background was recovered slower than theoretically expected in higher backcross generations because of genetic drag of the introgressed gene, i.e. Pi2. With the aid of a whole-genome SNP array, the negative genetic drag would be removed more efficiently and the genetic background of a recurrent parent would be recovered quicker in higher backcross generations. The desirable allele tms loci of C815S was difficult to track using the linked molecular markers. Up to now, the tms gene/s in $\mathrm{C} 815 \mathrm{~S}$ has not been identified yet although several

Table 4 The performance of main agronomic and grain quality traits of newly developed blast resistant TGMS lines and C815S

\begin{tabular}{|c|c|c|c|c|c|c|c|c|c|c|c|c|}
\hline TGMS line & DTH $^{a}$ & $\mathrm{PH}(\mathrm{cm})$ & PN & $\mathrm{PL}(\mathrm{cm})$ & NGP & SF (\%) & GW (g) & MRP (\%) & RGL (mm) & L/W & $\mathrm{GC}(\mathrm{mm})$ & $A C(\%)$ \\
\hline Hua1032S & 93.0 & 76.1 & 13.2 & $24.4^{* *}$ & 145.8 & $63.6^{* *}$ & 25.0 & 65.4 & 6.3 & 2.8 & $63.5^{* *}$ & $12.7^{*}$ \\
\hline Hua1033S & 93.0 & 75.9 & 12.6 & $23.5^{* *}$ & $167.1^{*}$ & $72.6^{* *}$ & 25.2 & 66.2 & 6.3 & 2.8 & $67.5^{* *}$ & $12.2^{*}$ \\
\hline Hua1034S & 97.0 & $83.7^{*}$ & 13.0 & $24.5^{* *}$ & $160.9^{*}$ & 38.0 & 25.6 & 68.2 & 6.4 & 2.8 & $62.0^{* *}$ & $15.0^{*}$ \\
\hline Hua1037S & 96.0 & 72.6 & 12.8 & $23.1^{*}$ & 150.9 & 47.1 & 25.9 & 66.9 & 6.5 & 2.7 & $76.5^{* *}$ & $15.4^{*}$ \\
\hline C815S & 96.0 & 77.2 & 11.0 & 21.0 & 137.2 & 41.5 & 23.7 & 65.7 & 6.4 & 2.7 & 47.5 & 10.4 \\
\hline
\end{tabular}

aDTH: days to heading, PH: plant height (cm), PN: panicle number, PL: panicle length $(\mathrm{cm}), \mathrm{NGP}$ : number of grains per panicle, SF: spikelet fertility (\%), GW: 1,000-grain weight (g), MRP: milling rice percentage, RGL: rice grain length, L/W: grain length-width ratio, GC: gel consistency, AC: amylose content, *, **Symbols followed after means indicate significant at the $5 \%$ or $1 \%$ significance level by the $T$-test. 
other tms genes in TGMS rice have been mapped (Hussain et al. 2012), and the tms gene mapping results were influenced by background, even they had same tms gene source, e.g. Guangzhan63S and Nongken58S (Ding et al. 2012; Liu et al. 2001; Lu et al. 2005; Xu et al. 2011; Zhang et al. 1994).

Heading date, a critical trait that determines cropping seasons and regional adaptability in rice, depends strongly on photoperiodic responses. More than 16 genes/QTLs have been identified as being involved in the photoperiodic flowering pathway in rice (Matsubara et al. 2008; Yano et al. 2001). Hd1, a major photoperiod sensitivity gene on chromosome 6, was tightly linked to a blast resistance gene, $P i-z^{t}$ (Yano et al. 1997; Yano et al. 2000), the allele at Pi2/Pi9 (Zhou et al. 2006). In our experiments, many combinations from C815S used as female parent were sensitive to photoperiod because they did not heading in normal season growth duration (data not shown). However, the combinations from the above same pollen parents and the newly developed TGMS lines harboring Pi2 gene could head like other normal varieties. These phenomena implied that no photoperiod sensitive gene replaced the photoperiod sensitive gene in C815S simultaneously when we introgressed the chromosome fragment including $\mathrm{Pi}$ gene from nonphotoperiod sensitive variety VE6219 into C815S.

Conventional disease resistance breeding is hard sledding, time-consuming, blindness compared with MAS which offers a powerful strategy to transfer genes from exotic germplasm into cultivated lines. It is important to note that introgression genes in rice should not lead to yield penalty or other drawbacks on important agronomic traits. But MAS only focused on one or several genes, several traits, ignore the comprehensive traits, so we should transvalue the agronomic traits of selected lines. The recently designed rice genomic SNP arrays (Yu et al. 2014; Chen et al. 2014) have offered molecular breeders excellent tools for the genetic background selection which could significantly reduce the recurrent cycles of backcrossing and help to break the negative genetic linkage between a target gene and poor agronomy trait. For TGMS lines, the most important trait is CTP of fertility-sterility alteration which related to safe hybrid rice seed and self seed production. In China, a TGMS line could not be released if its CTP was higher than $24^{\circ} \mathrm{C}$ of DMT. Seed multiplication will be very difficult if the CTP of a TGMS line was below $21^{\circ} \mathrm{C}$ of DMT. In our study, the CTPs of Hua1034S and Hua1037S were located at $22^{\circ} \mathrm{C}$ of DMT similar to the recurrent parent, C815S. However, Hua1032S and Hua1033S were located at $23^{\circ} \mathrm{C}$ of DMT. So, Hua1034S and Hua1037S can be used for hybrid seed production when the DMT during booting stage is over $22^{\circ} \mathrm{C}$ and can be used for TGMS line seed multiplication when below $22^{\circ} \mathrm{C}$. However, Hua1032S and Hua1033S can be used for hybrid seed production when the DMT during booting stage is over $23^{\circ} \mathrm{C}$ and can be used for seed multiplication when below $23^{\circ} \mathrm{C}$. Finally, Hua1037S was considered as excellent female parent for two-line blast resistant hybrid breeding because of its blast resistance, low CTP and better agronomic traits.

\section{Conclusions}

Rice blast disease is one of the most serious worldwide problems for rice production. Recently, it has become more serious and outspread, which urgently requires the development of rice blast resistant varieties. We successfully introgressed a broad-spectrum and durable rice blast resistance gene Pi2 into an elite TGMS line to develop four blast resistance TGMS lines by using a dualselection strategy of phenotypic and genotypic selection along with background screening to isolate improved breeding lines. These developed TGMS lines will be practical valuable for developing blast resistance twoline system hybrid rice in China.

\section{Methods}

\section{Plant materials}

C815S, an elite TGMS line widely used as female parent in two-line system hybrid rice breeding in China, but susceptible to blast was used as TGMS gene donor and recurrent parent. VE6219, a blast resistance breeding line (from the offspring between T1007 and C101A51) possessing $P i 2$ gene, was used for blast resistance gene donor parent. The CO39 variety was used as a susceptible control for rice blast evaluation.

\section{Molecular markers and PCR amplification}

Adoption of MAS was facilitated by using simple sequence repeat (SSR) marker RM527 for Pi2 (Chen et al. 2008). Total DNA was extracted according to the procedure of Dellaporta et al. (1983). PCR reactions were performed on a MyCycler ${ }^{\text {ra }}$ thermal cycler (BIO-RAD USA). Each $20 \mu \mathrm{l}$ PCR reaction mixture contained $20 \mathrm{ng}$ genomic DNA, $10 \mathrm{mM}$ Tris- $\mathrm{HCl}(\mathrm{pH} 9.0), 50 \mathrm{mM} \mathrm{KCl}$, $2.5 \mathrm{mM} \mathrm{MgCl}_{2}, 2 \mathrm{mM}$ dNTPs, $10 \mu \mathrm{M}$ each of the primer pair and 1 unit Taq DNA polymerase. Template DNA was initially denatured at $94^{\circ} \mathrm{C}$ for $5 \mathrm{~min}$ prior to $35 \mathrm{cy}-$ cles of denaturation at $94^{\circ} \mathrm{C}(30 \mathrm{~s})$, annealing at $55^{\circ} \mathrm{C}$ (30s), and extension at $72^{\circ} \mathrm{C}(45 \mathrm{~s})$. At the final step, the reaction mixture was incubated at $72^{\circ} \mathrm{C}$ for $5 \mathrm{~min}$ before the completion. The amplified products were then electrophoretically resolved on a $4 \%$ polyacrylamide gel in $1 \times$ TBE buffer.

\section{Rice blast evaluation}

The newly developed TGMS lines, C815S (TGMS gene donor), VE6219 (blast resistance gene donor) and CO39 
(blast susceptible CK) were inoculated in greenhouse by 62 isolates of M. oryzae from Zhejiang and Guangdong provinces, China. Leaf and neck blast resistance were identified under natural conditions by planting in the rice blast disease hotspot location, the Wangjia village of Yuan-An county, Hubei, China, where rice blast diseases were epidemic every year. The disease resistance reaction both in greenhouse and under natural fields were carried out according to standard evaluation system for rice (SES) (IRRI 2002).

\section{Genetic background profiling by RICE6K}

RICE6K, a whole-genome single nucleotide polymorphism (SNP) array, was used for genetic background profiling of newly developed TGMS line (Yu et al. 2014). RICE6K was developed based on Infinium technology, using representative SNPs selected from more than four million SNPs identified from resequencing data of more than 500 rice landraces. It contains 5102 SNP and InDel markers, about 4500 of which were of high quality in the tested rice lines producing highly repeatable results. For each line, total DNA was extracted from 20 dry seeds. DNA amplification, fragmentation, chip hybridization, single base extension, staining and scanning were conducted by Life Science and Technology Center, China National Seed Group Co., LTD (Wuhan, China), according to Infinium HD Assay Ultra Protocol (http://www. illumina.com/).

\section{Characterization of TGMS lines for fertility-sterility alteration under growth chamber}

100 seeds per line were sown at the nursery plots of Experimental Farm of HAU on May 10 of 2012. Uniform and healthy rice seedlings at the 5-leaf stage (about 25 days after sowing) were selected for transplanting of five single plants per hill per plastic pot and each plant was labeled with plastic tags. Care was taken with proper crop management to allow the plants in each plot to grow well and be uniform. Five growth chambers (Model: ZSX1500GS manufactured by The Shanghai Jing Wins and Scientific Equipment Co., Ltd., China) were adjusted for dry runs, one week prior to their actual use for the experiments. Light duration and relative humidity level was set to $14 \mathrm{~h}$ and $75 \%$ uniformly to all the five growth chambers while the daily mean temperatures were set for $21^{\circ} \mathrm{C}, 22^{\circ} \mathrm{C}, 23^{\circ} \mathrm{C}, 24^{\circ} \mathrm{C}$ and $25^{\circ} \mathrm{C}$, respectively. The temperature and light duration were carefully programmed to follow diurnal patterns at the same time achieve the required daily mean temperature and day light conditions. The plants were placed in growth chambers from 5 to 16 days after panicle initiation primordial stage. The plants were moved out from the growth chambers after 12 days of temperature treatment. The pollen grains collected from top five spikelets from each panicle per plant that headed during 5-16 days after the end of controlled growth chamber environment treatment were observed under microscope. The pollen sterility of each panicle was recorded according to the classification of pollen morphology upon IK-I staining of pollen grains (Virmani et al. 2003). The line with more than $99.5 \%$ of pollen sterility on an average was considered as completely sterile.

\section{Dynamic observation of pollen fertility-sterility alteration in the field}

120 seeds in each line were sown at 15-day intervals at the Experimental Farm of HAU. Forty uniform and healthy rice seedlings at the 5-leaf stage were transplanted in fields with a spacing of 20 by $25 \mathrm{~cm}$ between plants and rows. The pollen fertilities in each line from the top five spikelets of primary panicles were investigated dynamically with two-day intervals under microscope from 30 June to 1 October. The pollen sterility data were recorded with average of five panicles from each line. The daily mean temperature data was provided by the Agricultural Meteorology Department of HAU. Analysis of pollen sterility data in relation to temperature weather charts was carried out to determine the CTP of fertility-sterility alteration under natural conditions.

\section{Evaluation of agronomic and rice grain quality traits}

Thirty plants each of the newly developed TGMS lines and its recipient parent $\mathrm{C} 815 \mathrm{~S}$ were transplanted in the field during the winter season of 2011 at Rice Breeding Station of HAU, Lingshui County of Hainan province, China. Each plot comprised of three rows with 10 plants per row at planting density of $17 \mathrm{~cm}$ between plants and $20 \mathrm{~cm}$ between rows. The agronomic and rice quality traits were measured according to standard evaluation system for rice (IRRI, 2002). Five individuals in the middle of the second row in each plot were taken for measurements of agronomic traits, including days from sowing to heading, plant height, panicles per plant, panicle length, spikelets per panicle, spikelet fertility and weight of 1,000 grains. $T$-test was to detect statistical differences between developed TGMS line and recurrent parent. Harvested bulk seeds from each plot were used for analyzing rice grain quality traits that included milling rice percentage, rice grain length, grain length-width ratio, gel consistency and amylose content were also measured.

\section{Abbreviations}

TGMS: Thermo-sensitive genic male sterile; CMS: Cytoplasmic male sterility;

MAS: Marker assisted selection; SNP: Single nucleotide polymorphism;

SSR: Simple sequence repeat; Indel: Insertion-deletion; CTP: Critical

temperature point; DMT: Daily mean temperature. 


\section{Competing interests}

The authors declare that they have no competing interests.

\section{Authors' contributions}

JFJ carried out the experiments, MAS, characterization of fertility-sterility alteration and evaluation of agronomic and rice grain quality traits. TMT conceptualized the study and did blast evaluation. HHY and FSZ did background profiling by RICE6K. JFJ and TMT prepared manuscript together. All authors read and approved the final manuscript.

\section{Acknowledgments}

This research was supported by the Introduction of International Advanced Agricultural Science and Technology Program of China (948 Program, Grant No. 2012-G2), the National High Technology Research and Development Programs of China (863 Programs, "Breeding of New Varieties of Green Super Rice", Grant No. 2014AA10A604), and the Bill \& Melinda Gates Foundation "Green Super Rice for the Resources-Poor of Africa and Asia".

\section{Author details}

${ }^{1}$ National Key Laboratory of Crop Genetic Improvement, National Center of Plant Gene Research (Wuhan), Huazhong Agricultural University, Wuhan 430070, China. ${ }^{2}$ Life Science and Technology Center, China National Seed Group Co., Ltd., Wuhan 430206, China.

\section{Received: 2 November 2014 Accepted: 2 February 2015}

Published online: 12 February 2015

\section{References}

Bonman JM, Dedios TIV, Khin MM (1986) Physiological Specialization of Pyricularia-Oryzae in the Philippines. Plant Dis 70(8):767-769

Chen HD, Xie WB, He H, Yu HH, Chen W, Li J, Yu RB, Yao Y, Zhang WH, He YQ, Tang XY, Zhou FS, Deng XW, Zhang QF (2014) A high-density SNP genotyping array for rice biology and molecular breeding. Mol Plant 7(3):541-553

Chen HQ, Chen ZX, Ni S, Zuo SM, Pan XB, Zhu XD (2008) Pyramiding three genes with resistance to blast by marker assisted selection to improve rice blast resistance of Jin 23B (in Chinese with English summary). Chinese J Rice Sci 22(1):23-27

Dellaporta SL, Wood J, Hicks JB (1983) A plant DNA minipreparation: version II. Plant Mol Biol Rep 1(4):19-21

Deng YW, Zhu XD, Shen Y, He ZH (2006) Genetic characterization and fine mapping of the blast resistance locus Pigm(t) tightly linked to Pi2 and Pi9 in a broad-spectrum resistant Chinese variety. Theor Appl Genet 113(4):705-713, doi:10.1007/s00122-006-0338-7

Ding JH, Lu Q, Ouyang YD, Mao HL, Zhang PB, Yao JL, Xu CG, Li XH, Xiao JH, Zhang QF (2012) A long noncoding RNA regulates photoperiod-sensitive male sterility, an essential component of hybrid rice. Proc Natl Acad Sci U S A 109(7):2654-2659

Hayashi K, Hashimoto N, Daigen M, Ashikawa I (2004) Development of PCR-based SNP markers for rice blast resistance genes at the Piz locus. Theor Appl Genet 108(7):1212-1220, doi:10.1007/s00122-003-1553-0

Hussain AJ, Ali J, Siddiq EA, Gupta VS, Reddy UK, Ranjekar PK (2012) Mapping of tms 8 gene for temperature-sensitive genic male sterility (TGMS) in rice (Oryza sativa L.). Plant Breed 131(1):42-47

IRRI (2002) Standard evaluation system for rice (SES). International Rice Research Institute, Los Banos, Laguna, Philippines

Ishihara T, Hayano-Saito Y, Oide S, Ebana K, La NT, Hayashi K, Ashizawa T, Suzuki F, Koizumi S (2014) Quantitative trait locus analysis of resistance to panicle blast in the rice cultivar Miyazakimochi. Rice 7:2, doi:10.1186/s12284-014-0002-9

Jiang HC, Feng YT, Bao L, Li X, Gao GJ, Zhang QL, Xiao JH, Xu CG, He YQ (2012) Improving blast resistance of Jin 23B and its hybrid rice by marker-assisted gene pyramiding. Mol Breed 30(4):1679-1688

Liu G, Lu G, Zeng L, Wang GL (2002) Two broad-spectrum blast resistance genes, Pig(t) and Pi2(t), are physically linked on rice chromosome 6. Mol Genet Genomics 267(4):472-480, doi:10.1007/s00438-002-0677-2

Liu J, Wang X, Mitchell T, Hu Y, Liu X, Dai L, Wang GL (2010) Recent progress and understanding of the molecular mechanisms of the rice-Magnaporthe oryzae interaction. Mol Plant Pathol 11(3):419-427

Liu N, Shan Y, Wang FP, Xu CG, Peng KM, Li XH, Zhang Q (2001) Identification of an 85-kb DNA fragment containing pms1, a locus for photoperiod-sensitive genic male sterility in rice. Mol Genet Genomics: Mol Genet Genomics 266(2):271-275
Liu Y, Liu B, Zhu XY, Yang JY, Bordeos A, Wang GL, Leach JE, Leung H (2013) Fine-mapping and molecular marker development for Pi56(t), a NBS-LRR gene conferring broad-spectrum resistance to Magnaporthe oryzae in rice. Theor Appl Genet 126(4):985-998

Lu Q, Li XH, Guo D, Xu CG, Zhang Q (2005) Localization of pms3, a gene for photoperiod-sensitive genic male sterility, to a 28.4-kb DNA fragment. Mol Genet Genomics 273(6):507-511

Mackill DJ, Bonman JM (1992) Inheritance of Blast Resistance in near-Isogenic Lines of Rice. Phytopathology 82(7):746-749

Matsubara K, Kono I, Hori K, Nonoue Y, Ono N, Shomura A, Mizubayashi T, Yamamoto S, Yamanouchi U, Shirasawa K, Nishio T, Yano M (2008) Novel QTLs for photoperiodic flowering revealed by using reciprocal backcross inbred lines from crosses between japonica rice cultivars. Theor Appl Genet 117(6):935-945

Narayanan NN, Baisakh N, Cruz CMV, Gnanamanickam SS, Datta K, Datta SK (2002) Molecular breeding for the development of blast and bacterial blight resistance in rice cV. IR50. Crop Sci 42(6):2072-2079

Rajpurohit D, Kumar R, Kumar M, Paul P, Awasthi A, Basha PO, Puri A, Jhang T, Singh K, Dhaliwal HS (2011) Pyramiding of two bacterial blight resistance and a semidwarfing gene in Type 3 Basmati using marker-assisted selection. Euphytica 178(1):111-126

Skamnioti P, Gurr SJ (2009) Against the grain: safeguarding rice from rice blast disease. Trends Biotechnol 27(3):141-150, doi:10.1016/j.tibtech.2008.12.002

Suh JP, Jeung JU, Noh TH, Cho YC, Park SH, Park HS, Shin MS, Kim CK, Jena KK (2013) Development of breeding lines with three pyramided resistance genes that confer broad-spectrum bacterial blight resistance and their molecular analysis in rice. Rice 6:5, doi:10.1186/1939-8433-6-5

Virmani SS, Sun ZX, Mou TM, Ali J, Mao CX (2003) Two-line hybrid rice breeding manual. International Rice Research Institute, Los Banos, Laguna, Philippines

Xu JJ, Wang BH, Wu YH, Du PN, Wang J, Wang M, Yi CD, Gu MH, Liang GH (2011) Fine mapping and candidate gene analysis of ptgms2-1, the photoperiodthermo-sensitive genic male sterile gene in rice (Oryza sativa L.). Theor Appl Genet 122(2):365-372

Yano M, Harushima Y, Nagamura Y, Kurata N, Minobe Y, Sasaki T (1997) Identification of quantitative trait loci controlling heading date in rice using a high-density linkage map. Theor Appl Genet 95(7):1025-1032

Yano M, Katayose Y, Ashikari M, Yamanouchi U, Monna L, Fuse T, Baba T, Yamamoto K, Umehara Y, Nagamura Y, Sasaki T (2000) Hd1, a major photoperiod sensitivity quantitative trait locus in rice, is closely related to the arabidopsis flowering time gene CONSTANS. Plant Cell 12(12):2473-2483

Yano M, Kojima S, Takahashi Y, Lin HX, Sasaki T (2001) Genetic control of flowering time in rice, a short-day plant. Plant Physiol 127(4):1425-1429

Yu HH, Xie WB, Li J, Zhou FS, Zhang QF (2014) A whole-genome SNP array (RICE6K) for genomic breeding in rice. Plant Biotechnol J 12(1):28-37

Zhang QF, Shen BZ, Dai XK, Mei MH, Maroof MAS, Li ZB (1994) Using Bulked Extremes and Recessive Class to Map Genes for Photoperiod-Sensitive Genic Male-Sterility in Rice. Proc Natl Acad Sci U S A 91(18):8675-8679

Zhou B, Qu SH, Liu GF, Dolan M, Sakai H, Lu GD, Bellizzi M, Wang GL (2006) The eight amino-acid differences within three leucine-rich repeats between Pi2 and Piz-t resistance proteins determine the resistance specificity to Magnaporthe grisea. Mol Plant-Microbe Interact 19(11):1216-1228

Zhu X, Chen S, Yang J, Zhou S, Zeng L, Han J, Su J, Wang L, Pan Q (2012) The identification of Pi50(t), a new member of the rice blast resistance Pi2/Pi9 multigene family. Theor Appl Genet 124(7):1295-1304, doi:10.1007/s00122-012-1787-9

\section{Submit your manuscript to a SpringerOpen ${ }^{\circ}$ journal and benefit from:}

- Convenient online submission

Rigorous peer review

- Immediate publication on acceptance

- Open access: articles freely available online

- High visibility within the field

- Retaining the copyright to your article

Submit your next manuscript at springeropen.com 